\section{FULLY COMPLIANT AUTOCLAVE}

The DAC UNIVERSAL combination autoclave manufactured by Sirona fully complies with the HTM 01-05 regulations.

Automated cleaning and sterilisation of handpieces by combination autoclaves is considered to be superior to manual and semiautomated methods in terms of efficiency, economy and process reliability. The DAC UNIVERSAL simultaneously cleans, lubricates and sterilises up to six handpieces in one cycle after which the instruments are ready for use within 15 minutes. Alternatively, the instruments can be wrapped after cleaning and sterilisation and are then available for immediate use for up to 21 days. Cleaning and sterilisation can be carried out quickly which not only reduces the time spent by staff but also considerably reduces

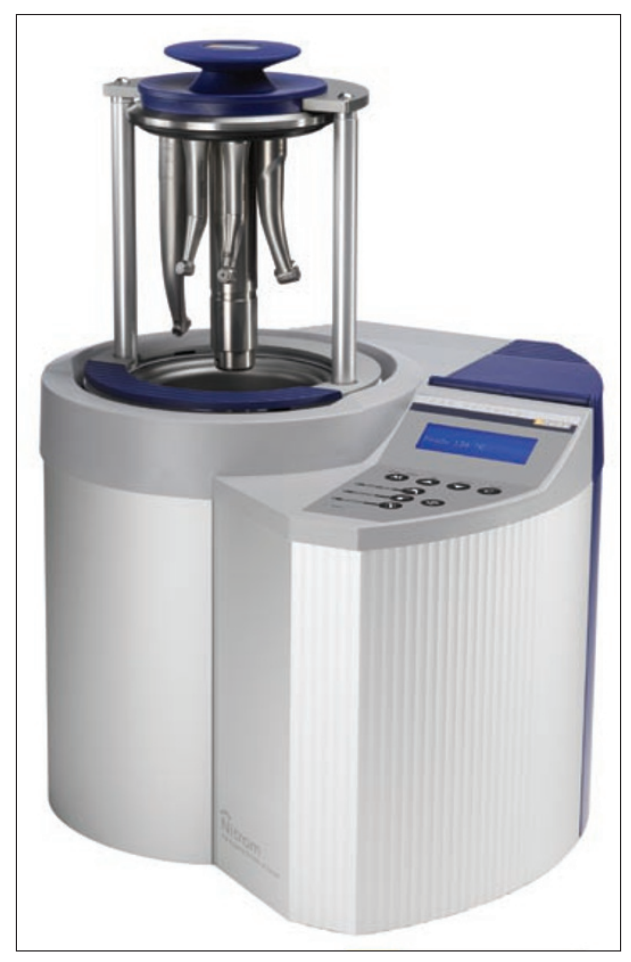

expenditure on handpieces. Moreover, the gentle cleaning and sterilisation process prevents damage to the instruments, thereby increasing their service life.

Reader response number $\mathbf{5 0}$

\section{KEEPYOUR WORKSTATION CLEAN}

Introdent have commissioned a new washable keyboard and mouse which incorporate disinfectant nano silver technology into the structure of their build material.

Introdent enables your practice's work station to be infection control efficient, from under $£ 40$. It is easy to meet the latest standards in infection control with these simple USB plug in and play keyboards and mice. Reader response number 52

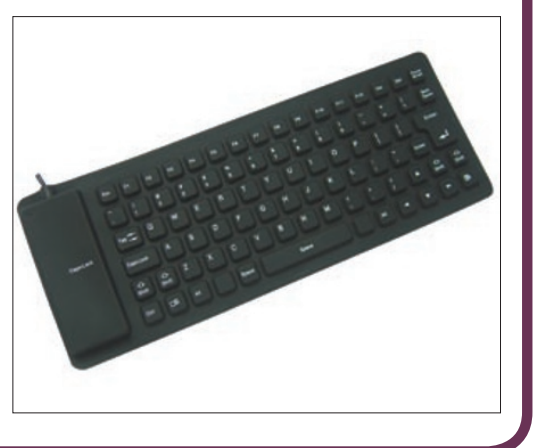

\section{BEAUTIFULLY CRAFTED SMILE SOLUTIONS}

Building on its portfolio of patient specific CAD/CAM restorative products, Biomet $3 i$ is expanding the boundaries of a traditional dental implant company by providing a series of innovative digital solutions from which laboratories, clinicians and patients can benefit.

Renishaw is a leading manufacturer of in-lab dental scanning systems offering comprehensive digital solutions and supplies precision engineering products to sectors as diverse as aerospace and neurosurgery.

Biomet $3 i$ and Renishaw offer: $3 i$ incise Copings and Frameworks; Renishaw contact scanners; $3 i$ incise CAD software and Renishaw in-lab milling machines.

Using the Renishaw scanner and $3 i$ incise CAD software, labs can obtain broader access to a wide range of dental milling options, including the ability to scan precision copy milled bar patterns. Labs using the ProceraForte Scanner can also benefit from all of these options by using the $3 i$ incise CAD software.

Reader response number 53
GET FRESH WITH MARKETING SOLUTIONS

Don't waste valuable time rebranding your practice's image when there are experts out there who can do a professional job on your behalf. THE FRESH knows how to give your practice the edge in the crowded dental market.

THE FRESH offers bespoke marketing solutions including corporate branding, website design, complete marketing campaigns, practice refurbishment, accountancy and recruitment. THE FRESH has a team of enthusiastic graphic and web designers dedicated to enabling your business to achieve its full potential.

THE FRESH website boasts over 150,000 hits every week.

Reader response number 51

\section{MAKE MIKE YOUR WEAPON OF CHOICE}

Schülke, the dental surgery infection control product manufacturer, has launched a new online game to help raise awareness of surface infection control.

With the help of Schülke's mascot for surgery surface disinfection, 'Mike' Mikrozid, dental professionals are invited to try their hand at ridding their surgery of the infective invaders using products from the mikrozid range as their weapons of choice.

Using the arrow keys on the keyboard to move around the virtual surgery and the space bar to kill invading bugs, dental professionals of all ages are sure to enjoy this light hearted and educational game.

The mikrozid range from Schülke includes well known names such as mikrozid AF, mikrozid sensitive and terralin protect. Reader response number 54

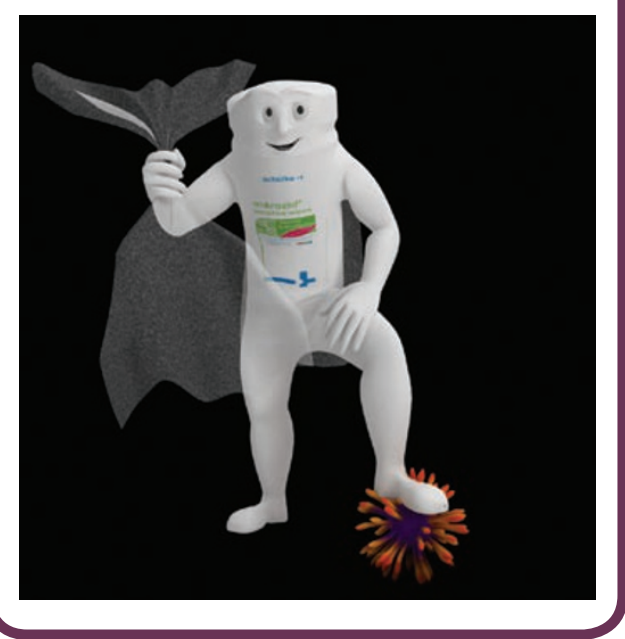

